\section{Eficácia de vacina inativada contra a doença de Aujeszky: infecção experimental de suínos}

\author{
Efficacy of an inactivated Aujeszky's disease virus vaccine: \\ experimental infection of pigs
}

CORRESPONDÊNCIA PARA:

Elenice Maria Sequetin Cunha Instituto Biológico

Av. Conselheiro Rodrigues Alves, 1.252

04014-001 - São Paulo - SP

e-mail: cunha@biologico.br

1 - Seção de Raiva e Encefalomielite, Instituto Biológico - SP

2 - Secão de Doenças de Suínos, Instituto Biológico - SP

3 - Departamento de Patologia da Faculdade de Medicina Veterinária e Zootecnia da USP - SP

4 - Departamento de Medicina Preventiva e Saúde Animal da Faculdade de Medicina Veterinária e Zootecnia da USP - SP

\author{
Elenice Maria Sequetin CUNHA ${ }^{1}$; Zélia Maria Pinheiro PEIXOTO' ${ }^{1}$; \\ Ivanete KOTAIT ${ }^{1}$; Josete Garcia BERSANO ${ }^{2}$; \\ Massaio Misuno ISHIZUKA ${ }^{3}$; Maria Regina BACCARO ${ }^{4}$
}

\title{
RESUMO
}

\begin{abstract}
Uma vacina experimental contra a doença de Aujeszky (DA), inativada e adsorvida em adjuvante oleoso, foi testada em relação à indução de imunidade, grau de proteção clínica e capacidade de reduzir a infecção, após desafio pela via intranasal. Grupos de 6 suínos, com 45 dias de idade, foram vacinados com uma ou duas doses de vacina, pelas vias intramuscular ou subcutânea, sendo mantido um grupo-testemunha, sem vacinação. Todos os suínos vacinados apresentaram títulos de anticorpos neutralizantes, detectáveis através da prova de soroneutralização, sendo estatisticamente superiores nos animais que receberam duas doses de vacina. A vacinação preveniu as manifestações clínicas da doença, após desafio, principalmente nos animais que receberam duas doses de vacina quando comparado com os que receberam 1 dose. Em todos os animais, vacinados e não-vacinados, foi possível a detecção do vírus da doença de Aujeszky (VDA) nas amígdalas, através da técnica de imunofluorescência direta. A porcentagem de amígdalas positivas nos suínos vacinados com duas doses foi inferior quando comparada àquela de suínos não-vacinados, no $2^{\circ}$ e $7^{\circ}$ dias pós-infecção. Em suínos vacinados com duas doses de vacina, pela via subcutânea, a taxa de infecção foi estatisticamente menor que naqueles vacinados com uma dose, pelas vias intramuscular ou subcutânea, e não-vacinadas.
\end{abstract}

UNITERMOS: Doença de Aujeszky; Vacinas inativadas; Tonsilas.

\section{INTRODUÇÃO}

A doença de Aujeszky (DA) ou pseudo-raiva pode causar grandes perdas em criações de suínos, devido à alta mortalidade perinatal e, em animais adultos, aos distúrbios respiratórios e à perda de peso. Desde a primeira ocorrência da doença no Brasil, surtos esporádicos foram descritos nos Estados de Minas Gerais ${ }^{9,26}$, Rio de Janeiro ${ }^{25}$, Rio Grande do $\mathrm{Sul}^{3}$ e São Paulo Estudos mais recentes relatam a ocorrência da doença em Santa Catarina, com elevada mortalidade de leitões ${ }^{18}$. No período de 19821986, estudos realizados por Kotait et al. ${ }^{11}$, demonstraram a existência de 66 focos da doença, disseminados por todo o Estadoe São Paulo, e levantamento sorológico realizado no mesmo Estado mostrou que 2,6\% dos animais testados apresentavam anticorpos contra o vírus da doença de Aujeszky (VDA) ${ }^{22}$. A vacinação de suínos contra a DA é uma prática comum na maioria dos países com ocorrência endêmica da doença. Embora a imunidade induzida pela vacinação de suínos não impeça a excreção viral após infecção ${ }^{12,23}$, a utilização de vacinas contra esta enfermidade tem como objetivo não só proteger os suínos contra as manifestações clínicas da doença, mas também prevenir o estabelecimento da infecção ou, se esta ocorrer, reduzir a eliminação viral ${ }^{10}$. Parece haver concordância na afirmação de que as vacinas atenuadas são mais eficazes que as inativadas ${ }^{10}$. No controle dos herpesvírus, no entanto, o uso de vacinas vivas atenuadas pode acarretar a transmissão horizontal do vírus, contribuindo, desta forma, para a propagação e manutenção do agente em populações animais? ${ }^{7}$ O menor poder imunogênico das vacinas inativadas pode, entretanto, ser contornado com o uso de adjuvantes. Delagneau et al. ${ }^{6}$, ao realizarem estudos comparativos entre uma vacina com hidróxido de alumínio e uma vacina oleosa (dupla emulsão), demonstraram que a taxa média de anticorpos dos animais vacinados com a vacina oleosa foi dez vezes mais elevada. Experimentos realizados pela Organização Panamericana da Saúde (OPAS), com vacinas contra a febre aftosa, evidenciaram que a dupla emulsão é particularmente indicada para a espécie suína, pois produz reações tissulares adversas com menor freqüência do que a vacina com emulsão primária ${ }^{14}$. As vacinas contra a DA são, na maioria das vezes, seguras e eficazes, podendo, no entanto, surgir falhas ocasionais de vacinação. Uma possível razão para que estas ocorram pode estar relacionada ao procedimento de vacinação, especialmente a via de inoculação utilizada para a aplicação de vacina ${ }^{8}$. Em uma região ou país, quando um programa de luta contra a doença é baseado na vacinação sistemática, é essencial a utilização de vacinas ou esquemas vacinais que limitem, ao mínimo, a replicação viral em suínos infectados após a vacinação. 
Dentro deste contexto, a proposta do presente estudo foi de verificar a eficácia de uma vacina inativada e oleosa (dupla emulsão) quando aplicada pelas vias intramuscular (IM) ou subcutânea (SC) e 1 ou 2 doses. Ainda, sua habilidade na proteção contra manifestações clínicas da doença e a capacidade de reduzir ou impedir a instalação da infecção pelo VDA virulento.

\section{MATERIAL E MÉTODO}

\section{Suínos}

Foram utilizados 30 suínos, nascidos de fêmeas não vacinadas contra a DA, provenientes de uma criação da Faculdade de Medicina Veterinária e Zootecnia da Universidade de São Paulo, Campus de Pirassununga. Os animais com 45 dias de idade, testados sorologicamente antes do início do experimento, mostraram-se soronegativos para anticorpos contra o VDA. Durante todo o período do experimento, os suínos foram mantidos em condições de isolamento.

\section{Antígenos virais}

A amostra IB 354/82, isolada de suíno proveniente do município de Artur Nogueira-SP, foi utilizada para o preparo da vacina. Os suínos e cobaios foram desafiados com a amostra de campo, também isolada de suíno, do município de Campo LimpoSP, IB 72/90.

\section{Vacina}

A vacina experimental foi obtida através da inoculação de 1.000 DICT50 do VDA (amostra IB 354/82), em garrafas do tipo Roux, contendo monocamadas de células VERO. Com a verificação de aproximadamente $80 \%$ de infecção, as culturas foram congeladas à temperatura de $-70^{\circ} \mathrm{C}$, para posterior titulação da infectividade viral, sendo o título do vírus determinado pelo método de Reed; Müench ${ }^{17}$.

Procedeu-se à inativação do vírus com $2 \mathrm{mM}$ de bietilenoimina (BEI), em uma concentração de $20 \mathrm{ml} / \mathrm{l}$ da suspensão, durante 24 horas a $37^{\circ} \mathrm{C}$ e sob agitação. Após a inativação, foi feita uma dupla emulsão água-óleo-água. Na emulsão primária, foram misturados Marcol 52 e Montanide 888 (90\% de Marcol e 10\% de Montanide), sendo esta mistura submetida a filtração esterilizante e, posteriormente, adicionada à suspensão virulenta já inativada, na proporção de $1 / 1$ juntamente com Merthiolate ${ }^{\circledR}$ (1/30.000), usado como conservante. Para o preparo da emulsão dupla, a primária (água-óleo) foi dispersa em uma fase aquosa, através de ação mecânica e de um emulsificante hidrofílico (Tween 80).

\section{Controle da vacina}

A emulsão foi submetida à prova da centrífuga e ao teste de estabilidade preconizados pela OPAS ${ }^{14}$.

Teste de esterilidade: empregou-se caldo simples e tioglicolato, para a verificação do crescimento de bactérias e ágarSabouraud, para a observação da possível presença de fungos. Os tubos contendo caldo simples e tioglicolato, inoculados com $0,5 \mathrm{ml}$ da amostra de vacina, foram mantidos em estufa a $37^{\circ} \mathrm{C}$, durante 96 horas, sendo realizado, após este período, um subcultivo. Os tubos com ágar-Sabouraud, inoculados com o mesmo volume de amostra vacinal, permaneceram à temperatura ambiente, por 7 dias. Foram mantidos nas mesmas condições tubos controles. Após o período de observação, os meios de cultura foram submetidos à coloração de Gram.

Teste de inocuidade ou vírus livre: realizado, in vivo, inoculando-se $0,03 \mathrm{ml}$ da vacina diluída $1 / 10$ em camundongos adultos de 21 dias de idade, e famílias de camundongos lactentes, de aproximadamente 4 dias, por via intracerebral (IC), e, in vitro, inoculando-se $1 \mathrm{ml}$ da mesma diluição em culturas de células VERO. Os camundongos inoculados foram observados durante 15 dias, para a verificação do aparecimento de sintomas da DA. As monocamadas celulares foram mantidas por um período de 5 dias em estufa a $37^{\circ} \mathrm{C}$, para visualização do efeito citopático, sendo que após esse período realizou-se uma segunda passagem, na mesma linhagem celular.

Teste de potência: vacinaram-se 10 cobaios, com peso aproximado de $350 \mathrm{~g}$, pela via IM, utilizando-se duas doses de vacina de $0,2 \mathrm{ml}$, com intervalo de 1 semana entre a primeira e segunda dose, sendo então coletadas de cada animal três amostras de sangue, por punção cardíaca, nos dias 7, 14 e 21. Vinte e quatro horas após a última colheita, os cobaios foram desafiados com 1.000 DL50 do VDA, por via IC. Outro grupo contendo 10 cobaios, não-vacinados e desafiados, foi utilizado como testemunha.

\section{Vacinação}

Foram constituídos 5 grupos de 6 animais cada, como segue: grupo I- animais vacinados com 2 doses de vacina, com 1 semana de intervalo, pela via intramuscular (IM); grupo II- animais vacinados com 2 doses de vacina, com 1 semana de intervalo, pela via subcutânea; grupo III- animais vacinados com 1 dose de vacina, pela via IM; grupo IV- animais vacinados com 1 dose de vacina, pela via SC; grupo V- controle sem vacinação. Os animais dos grupos III e IV receberam a dose única de vacina no dia em que aqueles dos grupos I e II receberam a $2^{\mathrm{a}}$ dose vacinal. A dose de vacina utilizada para cada animal foi de $2 \mathrm{ml}$.

\section{Amostras de soros}

Os animais de todos os grupos do experimento foram sangrados, assepticamente, através de incisão da veia marginal da orelha. Sete dias após a vacinação foi realizada a primeira colheita de sangue, sendo as demais, em um total de 3 , conduzidas com um intervalo de 7 dias.

\section{Teste de soroneutralização (TSN)}

Para a pesquisa de anticorpos neutralizantes (AN) contra o VDA foi utilizado o TSN descrita por Romero et al. ${ }^{19}$. Os soros foram testados, em triplicata, usando-se diluições de base 2. Eram testados, ainda, como controle, soro proveniente de suíno imunizado com o vírus da DA e um soro isento de anticorpos contra esta doença. Os títulos de AN foram expressos em valores do inverso da diluição que neutralizou 100 DICT50 do vírus. Para o cálculo final do título, aplicou-se o teste de Reed; Müench ${ }^{17}$. 


\section{Desafio}

Trinta dias após a vacinação, todos os suínos dos 5 grupos experimentais receberam $1 \mathrm{ml}$ da suspensão viral na dose de $0,5 \mathrm{ml}$ em cada narina, contendo 10.000 DICT50. Como controle, foram desafiados, igualmente, 2 leitões com 15 dias de idade, sem AN contra o VDA.

\section{Observação clínica}

Após o desafio com o VDA os suínos foram observados diariamente, por um período de 8 dias, para a verificação de eventuais manifestações clínicas, decorrentes da infecção. Assim, eram observadas a temperatura retal e uma escala de sintomas, que constava de: distúrbios respiratórios, como espirro, tosse e corrimento nasal; inapetência; ataxia; comprometimento do sistema nervoso central; e morte.

\section{Biópsia de amígdalas}

Foram realizadas 4 biópsias de amígdalas, no $2^{\circ}, 7^{\circ}, 14^{\circ}$, $21^{\circ}$ dias pós-desafio, com o auxílio de um aparelho desenvolvido no Japão, segundo técnica descrita para o diagnóstico da peste suína clássica $^{13}$.

\section{Preparo do conjugado}

Conjugado anti-VDA foi preparado a partir de um soro hiperimune produzido em suíno, seguindo a técnica preconizada por Stewart et al. ${ }^{27}$, com algumas modificações, tais como maior número de inoculações (dez) e a via de inoculação (intranasal).

\section{Teste de imunofluorescência (TIF)}

Os fragmentos de amígdalas foram congelados e submetidos a cortes de $4 \mu \mathrm{m}$ de espessura, em criostato, e posteriormente fixados em acetona, durante 20 minutos. Procedeu-se a coloração com anticorpos fluorescentes, por 30 minutos a $37^{\circ} \mathrm{C}$, e a leitura em microscópio de fluorescência. Como controle da reação, empregaram-se cortes de amígdala, provenientes de suíno infectado experimentalmente e de suíno livre de infecção.

\section{Análise estatística}

Para a avaliação dos níveis de anticorpos, foi utilizado o teste da mediana - análise de Fisher ${ }^{24}$. Para estimar a frequiência de detecção do VDA em amígdalas, empregou-se o cálculo de limites de confiança para $95 \%$ de confiança ${ }^{4}$.

\section{RESULTADOS}

\section{Avaliação da eficácia da vacina}

A suspensão virulenta revelou um título viral de $10^{7,8}$ DICT50/ml. Através da prova da centrífuga, observou-se a separação em 2 fases, a aquosa, na parte inferior do tubo, e a emulsão, na porção superior. A vacina mostrou-se estável por um período de 15 dias à temperatura de $37^{\circ} \mathrm{C}$ e por 5 dias a $56^{\circ} \mathrm{C}$. $\mathrm{O}$ controle microbiológico revelou que não houve turvação dos meios e a ausência de crescimento de colônias de fungos. A observação microscópica de lâminas coradas pelo método de Gram não mostrou presença de bactérias e fungos. Camundongos adultos e lactentes inoculados com a vacina não apresentaram nenhum sintoma decorrente de eventual infecção pelo VDA residual, durante o período de observação. Tanto na primeira como na segunda passagem, não foi observado efeito citopático nas monocamadas de células VERO, sendo a ausência de infecção viral, nestas células, confirmada pelo TIF.

A avaliação de AN em cobaios mostrou que: 77,8\% (7/9) eram reagentes 7 dias após vacinação, 88,9\% (8/9) depois de 14 dias, e $100 \%$ eram sororreagentes 21 dias pós-vacinação, com títulos que variavam de 8 a 64. Após o desafio, com 1.000 DL50 do VDA virulento homólogo, constatou-se a sobrevivência de 88,9\% (8/9) de cobaios no $6^{\circ}$ dia pós-infecção. Aqueles não-vacinados vieram a óbito 48-72 horas após o desafio.

\section{Resposta de suínos frente à vacinação}

Os dados apresentados na Tab. 1 mostram que todos os animais do grupo I apresentavam uma resposta humoral positiva 7 dias pós-vacinação e que a presença de anticorpos se mantinha no $14^{\circ}, 21^{\circ}$ e $28^{\circ}$ dias. No grupo II, de 6 animais testados, apenas 1 não apresentava $\mathrm{AN}$ detectáveis no $7^{\circ}$ e $14^{\circ}$ dias, porém no $21^{\circ} \mathrm{e}$ $28^{\circ}$ dias pós-vacinal todos os suínos eram reagentes. No Grupo III, notou-se que um animal apresentava anticorpos 7 dias após a vacinação e que dois mostravam-se reagentes no $14^{\circ}$ dia. Aos 21 dias pós-vacinação, apenas um suíno permanecia não-reagente, enquanto os demais apresentavam-se reagentes. No $28^{\circ}$ dia, todos os animais testados possuíam anticorpos. No grupo IV, observa-se que dois animais eram reagentes no $7^{\circ}$ dia pós-vacinação e que aos 14 dias dois suínos permaneciam não-reagentes. No $21^{\circ}$ e $28^{\circ}$ dias, todos os animais apresentavam anticorpos detectáveis. Os valores das medianas de títulos de anticorpos obtidas nos diferentes esquemas de vacinação, cujos resultados são apresentados na Tab. 1 e ilustrados na Fig. 1, mostram que as melhores respostas foram obtidas no $28^{\circ}$ dia pós-vacinação. Os suínos do grupo V, não-vacinados, não apresentaram AN detectáveis, em nenhuma das colheitas. A comparação das medianas das taxas de anticorpos (Tab. 1), obtidas para os diferentes grupos, mostra que os níveis

\section{Tabela 1}

Sorologia de suínos após vacinação com vacina inativada contra a doença de Aujeszky. São Paulo, 1997.

\begin{tabular}{|c|c|c|c|c|c|c|c|c|c|}
\hline \multirow[t]{2}{*}{ Grupo } & \multirow{2}{*}{$\begin{array}{c}\mathrm{N}^{\circ} \mathrm{de} \\
\text { animais } \\
\text { Vacinados }\end{array}$} & \multicolumn{4}{|c|}{$\begin{array}{l}\text { Número de animais } \\
\text { com TSN* } 2 \text { DPV }\end{array}$} & \multicolumn{4}{|c|}{$\begin{array}{l}\text { Mediana dos títulos } \\
\text { de anticop os DPV }\end{array}$} \\
\hline & & 7 & 14 & 21 & 28 & 7 & 14 & 21 & 28 \\
\hline 1 & 6 & 6 & 6 & 6 & 6 & 6 & 6 & 8 & 21,5 \\
\hline II & 6 & 5 & 5 & 6 & 6 & 6 & 5 & 7 & 21 \\
\hline III & 6 & 1 & 2 & 5 & 6 & $<2$ & $<2$ & 2 & 7,5 \\
\hline IV & 6 & 2 & 4 & 6 & 6 & $<2$ & 2,5 & 2,5 & 6,5 \\
\hline V & 0 & 0 & 0 & 0 & 0 & 0 & 0 & 0 & 0 \\
\hline
\end{tabular}

Grupo I - 2 doses IM; Grupo II - 2 doses SC; Grupo III - 1 dose IM; Grupo IV - 1 dose SC; Grupo V - não-vacinado;

DPV - dias pós-vacinação; * TSN - título soroneutralizante. 
CUNHA, E.M.S.; PEIXOTO, Z.M.P.; KOTAIT, I.; BERSANO, J.G.; ISHIZUKA, M.M.; BACCARO, M.R. Eficácia de vacina inativada contra a doença de Aujeszky:

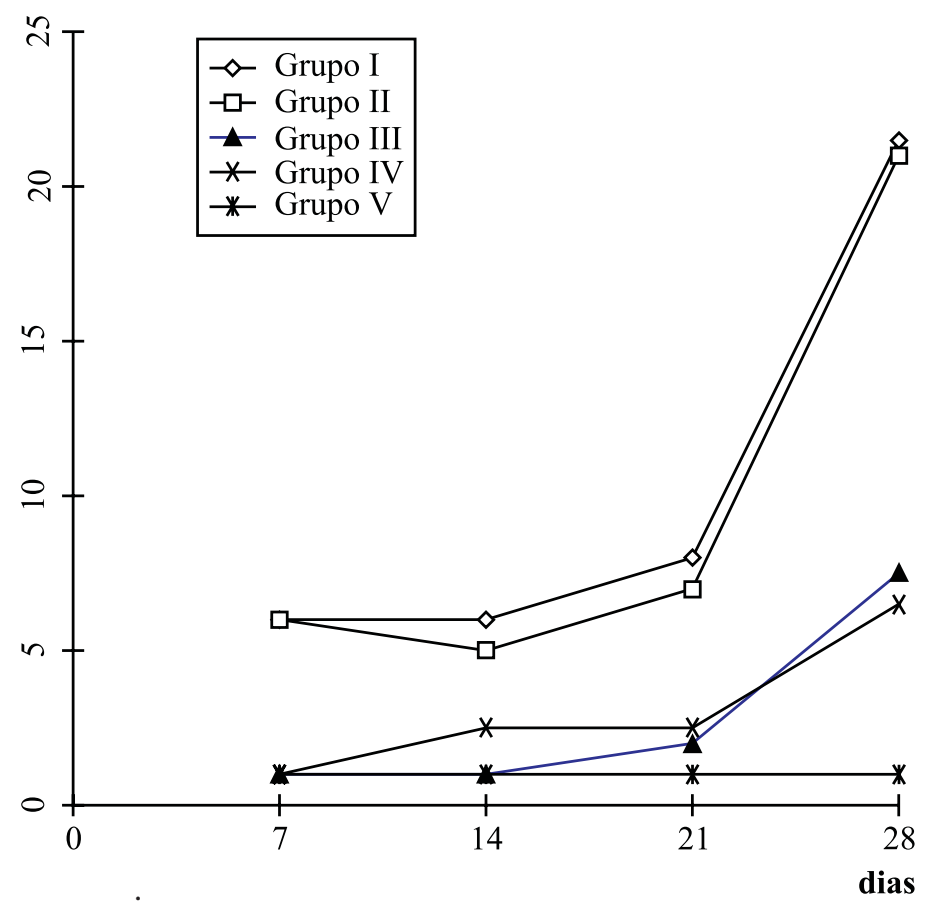

Figura 1

Mediana dos títulos de anticorpos contra o vírus da doença de Aujeszky, segundo os dias após vacinação. Grupo I: 2 doses IM; Grupo II - 2 doses SC; Grupo III - 1 dose IM; Grupo IV - 1 dose SC; Grupo V - nãovacinados.

de anticorpos para o grupo I e o grupo II, de um lado, e dos grupos III e IV, por outro lado, dispensam qualquer elaboração estatística em decorrência dos valores próximos das medianas para cada momento (dias pós-vacinação). Aplicou-se o teste da mediana com aproximação de Fisher, para comparar os resultados dos grupos I e III e dos grupos II e IV, para cada momento (dias pós-vacinação) e os resultados para "p" de Fisher mostraram-se significantes ao nível de rejeição adotada $(\alpha=0,05)$

\section{Observações clínicas de suínos pós-desafio}

A temperatura retal média, entre o $2^{\circ}$ e o $5^{\circ}$ dias pósdesafio, nos animais não-vacinados, foi $40,1^{\circ} \mathrm{C}$ a $40,2^{\circ} \mathrm{C}$, enquanto nos suínos vacinados foi $39,5^{\circ} \mathrm{C}$ a $40^{\circ} \mathrm{C}$, no mesmo período. Observou-se, ainda, que a média da temperatura, em todos os grupos, atingiu um pico no $3^{\circ}$ dia pós-infecção. As observações referentes à sintomatologia respiratória mostrou que no $4^{\circ}$ dia pós-desafio um suíno do grupo III apresentava distúrbios respiratórios, como espirro, tosse e corrimento nasal. Cinco dias após o desafio, dois animais do grupo testemunha manifestavam os mesmos sinais. No $6^{\circ}$ dia, um terceiro suíno do grupo controle e mais um animal do grupo III e um suíno do grupo IV tinham os mesmos sintomas. Ressalta-se que nenhum animal dos grupos I e II manifestou distúrbios respiratórios. A anorexia foi notada em todos os animais desafiados, entre o $3^{\circ}$ e o $7^{\circ}$ dias pósdesafio, o que pôde ser constatado pelo menor consumo de ração oferecida. Os dois leitões utilizados para o teste de virulência da amostra empregada no desafio foram a óbito 48-72 horas após a descarga viral.

\section{Tabela 2}

Detecção do vírus da doença de Aujeszky em amostras de amígdalas através da técnica de imunofluorescência direta, segundo o grupo experimental e dias após desafio. São Paulo, 1997.

\begin{tabular}{rcccccc}
\hline Dias & \multicolumn{5}{c}{ Grupos } \\
\cline { 2 - 7 } após \\
Desafio & $\mathrm{I}$ & $\mathrm{I}$ & $\mathrm{III}$ & $\mathrm{IV}$ & $\mathrm{V}$ \\
\hline $\mathrm{P}$ & $0(0 \%)$ & $0(0 \%)$ & $3(60 \%)$ & $4(66,7 \%)$ & $4(80 \%)$ \\
2 & $\mathrm{~N}$ & $5(100 \%)$ & $6(100 \%)$ & $2(40 \%)$ & $2(33,3 \%)$ & $1(20 \%)$ \\
& $\mathrm{T}$ & 5 & 6 & 5 & 6 & 5 \\
\hline & $\mathrm{P}$ & $1(16,7 \%)$ & $0(0 \%)$ & $4(66,7 \%)$ & $5(83,3 \%)$ & $4(80 \%)$ \\
7 & $\mathrm{~N}$ & $5(83,3 \%)$ & $5(100 \%)$ & $2(33,3 \%)$ & $1(16,7 \%)$ & $1(20 \%)$ \\
& $\mathrm{T}$ & 6 & 5 & 6 & 6 & 5 \\
\hline & $\mathrm{P}$ & $5(83,3 \%)$ & $5(83,3 \%)$ & $6(100 \%)$ & $6(100 \%)$ & $5(83,3 \%)$ \\
14 & $\mathrm{~N}$ & $1(16,7 \%)$ & $1(16,7 \%)$ & $0(0 \%)$ & $0(0 \%)$ & $1(16,7 \%)$ \\
& $\mathrm{T}$ & 6 & 6 & 6 & 6 & 6 \\
\hline & $\mathrm{P}$ & $6(100 \%)$ & $3(50 \%)$ & $4(80 \%)$ & $5(83,3 \%)$ & $6(100 \%)$ \\
21 & $\mathrm{~N}$ & $0(0 \%)$ & $3(50 \%)$ & $1(20 \%)$ & $1(16,7 \%)$ & $0(0 \%)$ \\
& $\mathrm{T}$ & 6 & 6 & 5 & 6 & 6 \\
\hline
\end{tabular}

Grupo I - 2 doses IM; Grupo II - 2 doses SC; Grupo III - 1 dose IM; Grupo IV - 1 dose SC;

Grupo V - não-vacinado;

$\mathrm{P}-\mathrm{n}^{\mathrm{o}}$ de animais positivos;

$\mathrm{N}-\mathrm{n}^{\circ}$ de animais negativos;

$\mathrm{T}-\mathrm{n}^{\mathrm{o}}$ de animais biopsiados.

\section{Tabela 3}

Resultado (\%) da biópsia de amígdala, segundo grupo experimental de suínos, para detecção do vírus da doença de Aujeszky, pela prova de imunofluorescência direta, São Paulo, 1997.

\begin{tabular}{ccccc}
\hline Grupos & $\begin{array}{c}\text { No de }^{\circ} \\
\text { Biópsias }\end{array}$ & Positivo & Negativo & $\begin{array}{c}\% \text { de } \\
\text { positividade }\end{array}$ \\
\hline I & 23 & 12 & 11 & 52,2 \\
II & 23 & 08 & 15 & 34,8 \\
III & 22 & 17 & 05 & 73,3 \\
IV & 24 & 20 & 04 & 83,3 \\
V & 22 & 19 & 03 & 86,4 \\
\hline
\end{tabular}

Grupo I - 2 doses IM;

Grupo II - 2 doses SC;

Grupo III - 1 dose IM;

Grupo IV - 1 dose SC;

Grupo V - não-vacinados.

\section{Avaliação da presença do VDA em amígdalas de suínos}

O resultado da pesquisa do antígeno viral através do TIF, em cortes de amígdalas, pode ser observado na Tab. 2. Dois dias após o desafio, o VDA não foi detectado na amígdala de nenhum dos animais dos grupos I e II, sendo que os suínos dos grupos III e IV e $\mathrm{V}$ apresentavam animais positivos. Nenhum dos animais que recebeu 2 doses de vacina, por via SC mostrava reação positiva 7 dias após infecção, enquanto nos demais grupos o VDA pôde ser detectado. $\mathrm{Na} 3^{\mathrm{a}}$ e $4^{\mathrm{a}}$ colheitas, realizadas aos 14 e 21 dias pósdesafio, respectivamente, todos os grupos estudados apresentavam animais positivos. Verifica-se, ainda, na Tab. 2, que na primeira 
colheita o grupo III e o grupo IV apresentavam $60 \%$ e $66,7 \%$ de suínos positivos, respectivamente, e o grupo testemunha, $80 \%$. No $7^{\circ}$ dia pós-desafio, o grupo I contava com $16,7 \%$ de animais reagentes, os grupos III e IV tiveram suas porcentagens aumentadas para $66,7 \%$ e $83,3 \%$, respectivamente, enquanto no grupo $\mathrm{V}$ esta porcentagem foi mantida. Na $3^{\text {a }}$ colheita, a porcentagem de animais positivos foi superior a $80 \%$ em todos os grupos estudados. A detecção do VDA, 21 dias pós-desafio atingiu níveis acima de $80 \%$ em todos os grupos, com exceção do grupo II, que apresentou $50 \%$ de animais positivos. A análise estatística com base no cálculo e comparação dos limites de confiança mostrou que não houve diferença significante entre os grupos I e II e que os grupos III, IV e V apresentaram maior porcentagem de deteç̧ão do VDA que os grupos I e II, no $2^{\circ}$ e $7^{\circ}$ dias pós-desafio. Analisando o número de biópsias positivas de amígdalas em cada um dos grupos experimentais, verifica-se que em $52,2 \%$ das amostras do grupo I, $34,8 \%$ do grupo II, $72,3 \%$ do grupo III, $83,3 \%$ do grupo IV e $86,4 \%$ do grupo V foi possível a detecção do VDA (Tab. 3). A análise estatística com base no mesmo cálculo do caso anterior mostra que o grupo I não diferiu significativamente, de um lado, do grupo II e de outro lado dos grupos III, IV e V. No entanto, o grupo II diferiu significativamente em relação aos grupos III, IV e V, que apresentaram maior detecção do VDA.

\section{DISCUSSÃO E CONCLUSÕES}

As vacinas devem ser avaliadas por testes que comprovem sua inocuidade e o seu poder imunogênico, em animais de laboratório e na espécie-alvo. No presente estudo, a vacina experimental inativada, produzida em culturas celulares e com emulsão oleosa (dupla), foi testada em suínos e em cobaios, os quais apresentaram alta suscetibilidade ao desafio, mostrando-se adequados para a avaliação do poder imunogênico da vacina experimental, sendo sua utilização bastante prática.

As manifestações clínicas conferidas pelo desafio viral em suínos vacinados podem ser avaliadas por vários parâmetros: aumento da temperatura retal, perda de peso, distúrbios respiratórios e mortalidade ${ }^{29}$. Pensaert et al.$^{16}$, concluíram que os sinais clínicos são muitas vezes difíceis de ser usados como critério na DA, porque estes não podem ser facilmente medidos, mas que a febre pode ser considerada como um parâmetro objetivo e uma indicação direta da severidade da doença. Para a avaliação da proteção conferida pela vacina utilizada, no presente estudo, foram selecionados alguns desses critérios. A temperatura retal após o desafio era mais elevada nos suínos não-vacinados que naqueles que receberam 1 ou 2 doses vacinais, durante todo o período observado. Entre os animais vacinados, verificou-se que não houve diferença de temperaturas, independentemente do título de anticorpos no momento do desafio, contrariando os achados por Pensaert et al. ${ }^{16}$, que concluíram que a febre diminui com o aumento no título de anticorpos neutralizantes. Enfocando-se os distúrbios respiratórios, induzidos pela infecção com o VDA, pode-se considerar que é comum o aparecimento de pneumonia causada pelo próprio agente viral ou por infecções bacterianas secundárias ${ }^{2}$. Pode-se inferir, pelos resultados obtidos, que os suínos que receberam 2 doses de vacina não manifestaram sintomas indicativos de comprometimento respiratório, enquanto $25 \%$ dos animais vacinados com 1 dose e $50 \%$ daqueles sem vaci- nação mostraram distúrbios do tipo espirro, tosse e corrimento nasal. Isto indica que duas doses vacinais protegeram $100 \%$ dos animais desafiados, com a amostra virulenta do VDA, contra as manifestações respiratórias da doença.

A vacinação contra a DA induz a formação de anticorpos séricos, os quais protegem os suínos contra uma exposição letal do vírus $^{31}$. No presente estudo, a resposta imune do tipo humoral pôde ser demonstrada na totalidade dos animais após a vacinação contra a DA. Analisando-se os resultados obtidos, verifica-se que, dos animais vacinados com 2 doses de vacina, 100\% dos suínos do grupo I apresentavam anticorpos detectáveis já aos 7 dias pós-vacinação, e com exceção de um suíno que se manteve negativo no $7^{\circ}$ e $14^{\circ}$ dia, o mesmo pode ser concluído para o grupo II. Em relação aos animais vacinados com 1 dose de vacina, conclui-se que só no $21^{\circ}$ dia (grupo III) e $28^{\circ}$ dia (grupo IV) $100 \%$ de animais eram reagentes. Enfocando-se as medianas dos títulos da resposta humoral (Tab. $1 \mathrm{e}$ Fig. 1), observa-se uma homogeneidade nos resultados obtidos entre os componentes dos grupos I e II e os grupos III e IV. No entanto, os valores obtidos nos animais que receberam 2 doses vacinais foram superiores àqueles dos suínos que receberam 1 dose. Estes dados, analisados em seu conjunto, sugerem que a resposta imune humoral teve um aparecimento mais precoce e de maior magnitude nos grupos experimentais que receberam 2 doses de vacina. Vannier ${ }^{28}$, relatou que uma dupla vacinação é necessária para a promoção de uma imunidade sólida com vacina inativada. Ainda, estudos realizados por Alva-Valdes et al. ${ }^{1}$, concluíram que $89 \%$ dos animais vacinados com 2 doses de vacina inativada eram sororreagentes no $1^{\circ}$ mês pós-vacinação.

Embora numerosos estudos tenham sido realizados para o esclarecimento da proteção específica contra os herpesvírus, a natureza precisa desses mecanismos permanece obscura. Apesar dessa incerteza, os anticorpos desempenham um papel importante na proteção, mas a correlação entre títulos de anticorpos e proteção permanece incompleta ${ }^{10}$. Estudos pioneiros realizados por Sabó ${ }^{20}$, demonstraram que animais vacinados podiam ser infectados com o VDA, embora o autor sugerisse uma direta correlação entre a presença de AN no soro e o desaparecimento do vírus do organismo animal. $\mathrm{O}$ mesmo autor concluiu, ainda, que AN são incapazes de prevenir a persistência do vírus virulento em uma propriedade endêmica. AlvaValdes et al. ${ }^{1}$, comparando o isolamento do vírus da DA em suínos vacinados com uma vacina inativada e suínos não-vacinados, demonstraram que o VDA foi isolado em $42,8 \%$ dos suínos não-vacinados e 7\% dos animais vacinados, 7 dias pós-desafio, e que aos 60 dias após o desafio a porcentagem de recuperação viral nos suínos não-vacinados era de $7 \%$ enquanto não foi possível o isolamento viral em nenhum dos animais vacinados. Estudando 11 vacinas vivas e deletadas em um de seus genes, Vannier et al..$^{30}$, concluíram que aquelas que melhor limitaram a eliminação viral também conferiram títulos mais elevados de anticorpos neutralizantes. Dados contraditórios, no entanto, foram relatados por Martin et al. ${ }^{12}$, os quais concluíram que a proteção de suínos vacinados não está correlacionada com títulos de anticorpos sistêmicos.

O papel da amígdala como sítio primário de multiplicação do VDA, após infecção, foi verificado em estudos realizados por Sabó et al. ${ }^{21}$, sendo sua presença neste tecido de grande importância na epidemiologia da doença. A análise do VDA na amígdala de suínos vacinados e não-vacinados no presente trabalho mostra que o 
CUNHA, E.M.S.; PEIXOTO, Z.M.P.; KOTAIT, I.; BERSANO, J.G.; ISHIZUKA, M.M.; BACCARO, M.R. Eficácia de vacina inativada contra a doença de Aujeszky: infecção experimental de suínos. Braz. J. vet. Res. anim. Sci., São Paulo, v. 35, n. 4, p. 188-194, 1998.

estabelecimento da infecção pelo VDA pôde ser demonstrado em suínos desafiados, com ou sem anticorpos neutralizantes. No entanto, animais vacinados com 2 doses de vacina e que apresentavam uma quantidade maior dessas imunoglobulinas no momento do desafio, infectavam-se mais tardiamente que aqueles vacinados com 1 dose e o grupo testemunha não-vacinado. Esses resultados confirmam aqueles obtidos por Alva-Valdes et al. ${ }^{1}$, que, comparando os dados obtidos, através da IF em amígdalas, de suínos vacinados, com vacina inativada, e de animais não-vacinados, detectaram $50 \%$ de suínos positivos no grupo não-vacinado e nenhuma positividade no grupo vacinado, 7 dias após o desafio com o vírus da DA. Os animais, com níveis menores de anticorpos, ou seja, vacinados com 1 dose de vacina, não mostravam diferença significante em relação à infecção, em nenhum momento, quando comparada à do grupo testemunha. Embora não houvesse diferença significante na taxa de AN pós-vacinais, no momento do desafio, entre os animais que receberam duas doses vacinais pela via IM e SC, os valores da detecção do VDA em amígdalas dos animais vacinados com 2 doses de vacina pela via SC mostravam-se estatisticamente mais protegidos quando comparados àqueles vacinados com 1 dose e o grupo testemunho. Este fato sugere que a aplicação de 2 doses da vacina pela via SC mostrou melhor desempenho no tocante à proteção contra a infecção. Resultados semelhantes foram obtidos por Pensaert et al. ${ }^{15}$, quando, em um estudo comparativo entre várias vacinas, concluíram que animais de 2 grupos experimentais apresentando a mesma taxa média de título de anticorpos, no momento do desafio, comportaram-se de maneira diversa em relação à eliminação viral, ou seja, em um dos grupos esta foi mais suprimida, sugerindo que outros mecanismos imunes, como o mediado por células, devem ser considerados.

A técnica de biópsia de amígdala, para a pesquisa do VDA em suínos vacinados e infectados, proposta neste estudo, pode ser de grande utilidade para estudos epidemiológicos da doença em nosso meio, auxiliando na detecção de suínos portadores, sem a necessidade do sacrifício de animais.

\section{SUMMARY}

An experimental inactivated, oil assisted Aujeszky's disease virus vaccine was tested for its ability to induce immunity, clinical protection level and reduction of viral infection after challenge by the nasal route. Groups of 6 pigs, 45 days-old, were vaccinated once or twice, by either intramuscular or subcutaneous routes. A group of unvaccinated animals was used as control. All the vaccinated pigs developed neutralizing antibodies, detected by serum-neutralization test. In pigs vaccinated twice the levels of neutralizing antibodies were higher than in pigs vaccinated once, and this difference was statistically significant. In vaccinated animals, the severity of clinical signs decreased with increasing antibodies titres. Aujeszky's disease virus was detected in tonsils of vaccinated and unvaccinated pigs by immunofluorescence method. However, the rate of positive tonsils in pigs vaccinated twice was reduced when compared with unvaccinated pigs on the $2^{\text {nd }}$ and $7^{\text {th }}$ days post-infection. The level of infection was statistically reduced in twice vaccinated pigs by subcutaneous route as compared with vaccinated once and unvaccinated animals.

UNITERMS: Aujeszky's disease; Inactivated vaccines; Tonsils.

\section{REFERÊNCIAS BIBLIOGRÁFICAS}

1- ALVA-VALDES, R.; GLOCK, R.D.; KLUGE, J.P.; HILL, H.T. The effects of challenge on the humoral and cellular immune responses in pseudorabies vaccinated swine. Can. J. Comp. Med., v.47, n.4, p.451-5, 1983.

2-BASKERVILLE, A. The histopathology of pneumonia produced by aerosol infection of pigs with a strain of Aujeszky's disease virus. Res. Vet. Sci., v.12, n.6, p.5902, 1971.

3- BAUER, A.G. Primeira constatação do mal de Aujeszky no Rio Grande do Sul. Arqu. Inst. Pesq. Vet. Desidério Finamor, v.1, p.15-6, 1955.

4- BERQUÓ, E.S. Bioestatística. São Paulo : EPU, 1980. 325p.

5- CARNEIRO, V. Distribuição geográfica e frequiência da doença de Aujeszky no Brasil. Biológico, v.16, n.3, p.49-58, 1950.

6- DELAGNEAU, J.F.; TOMA, B.; VANNIER, P.; LOQUERIE, R.; PRUNET, P.; TILLON, J.P. Immunisation contre la maladie d'Aujeszky a l'aide d'un nouveau vaccin huileux. Rec. Méd. Vét., v.151, n.3, p.567-75, 1975.

7- DE LEEUW, P.W.; TIESSINK, J.W.A. Evaluation of Aujeszky's disease virus vaccines. In: INTERNATIONAL PIG VETERINARY SOCIETY, Copenhagen, Denmark, 1980. Proceedings. p.112.

8- HASEBE, H.; OSORIO, F.A.; HOGG, A.; LIAUW, H.; BARTKOSKI, M.J.; SUGIYAMA, M. Influence of vaccination route on the efficacy of Aujeszky's disease deletion-mutant vaccine. J. Vet. Med. Sci., v.54, n.4, p.693$8,1992$.
9- HIPÓLITO, O.; LAMAS DA SILVA, J.M.; BATISTA Jr., J.A.; LIMA, S.N. A doença de Aujeszky em suínos em Minas Gerais. Arqu. Esc. Sup. Vet., Minas Gerais, v.13, p.61-6, 1960/61.

10- KIMMAN, T.G. Immunological protection against pseudorabies virus. In: AUJESZKY'S DISEASE. O.I.E. Bangkok, Thailand, 1994. Symposium. p.11-22.

11- KOTAIT, I.; PEIXOTO, Z.M.P.; CUNHA, E.M.S.; QUEIROZ, L.H.; SOUZA, M.C.A.M.; BERSANO, J.G. Focos da doença de Aujeszky no Estado de São Paulo no período de 1982-1986. Arqu. Inst. Biol., São Paulo, v.53, n.1/4, p.65$70,1986$.

12-MARTIN, S.; WARDLEY, R.C.; DONALDSON A.I. Functional antibody responses in pigs vaccinated with live and inactivated Aujeszky's disease virus. Res. Vet. Science, v.41, n.3, p.331-5, 1986.

13- NOBUTO, K.; SATO, U.; SAWADA, M. An instrument for harvesting tonsillar material for diagnosis of hog cholera. Nat. Inst. An. Health Quart., v.10, n.2, p.94-5, 1970.

14- OPAS - ORGANIZACIÓN PANAMERICANA DE LA SALUD. Producción, control de calidad y uso de vacunas con adyuvante oleoso contra la fiebre aftosa, Rio de Janeiro : OPAS, 1987, 260p.

15- PENSAERT, M.B.; DE SMET, K.; DE WAELE, K. Extent and duration of virulent virus excretion upon challenge of pigs vaccinated with different glycoproteindeleted Aujeszky's disease vaccines. Vet. Microbiol., v.22, n.2/3, p.107-17, 1990.

16- PENSAERT, M.B.; VANDEPUTTE, J.; ANDRIES, K. Oronasal challenge of fattening pigs after vaccination an inactivated Aujeszky's disease vaccine. Res. Vet. Sci., v.32, n.1, p.12-6, 1982. 


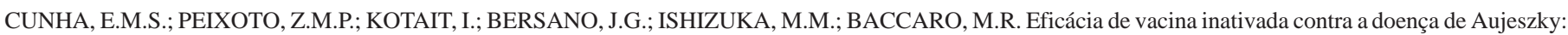
infecção experimental de suínos. Braz. J. vet. Res. anim. Sci., São Paulo, v. 35, n. 4, p. 188-194, 1998.

17- REED. L.J.; MUENCH, H. A simple method of estimating fifty percent endpoints American J. Hyg., v.27, p.493-7, 1938.

18- ROMERO, C.H. A doença de Aujeszky: I. Avanços na pesquisa da doença de Aujeszky II. Situação da doença no país. In: CONGRESSO LATINO DE VETERINÁRIOS ESPECIALISTAS EM SUÍNOS - CONGRESSO BRASILEIRO DE VETERINÁRIOS ESPECIALISTAS EM SUÍNOS, 2., Rio de Janeiro, 1985. Anais. p.23-7.

19- ROMERO, C.H.; ROWE, C.A.; FLORES, R.S.; BRENTANO, L.; MARQUES, J.L. Erradicação do vírus da doença de Aujeszky de plantéis de reprodutores suínos através da testagem e eliminação de suínos com anticorpos. Pesq. Vet. Bras., v.6, n.1, p.1-4, 1986.

20- SABÓ, A. Persistence of perorally administered virulent pseudorabies virus in the organism of non-immune and immunized pigs. Acta Virol., v.13, p.269-77, 1969.

21- SABÓ, A.; RAJKANI, J.; BLASKOVIC, D. Studies on the pathogenesis of Aujeszky's disease. IDistribution of virulent virus in piglets after peroral infection. Acta Virol., v.12, n.3, p.214-21, 1968.

22-SÃO PAULO (Estado). Secretaria da Agricultura e Abastecimento. Coordenadoria de Asssistência Técnica Integral - CATI. Diagnóstico da doença de Aujeszky no Estado de São Paulo. Campinas : CATI, 1986. 76p. (Documento Técnico CATI, 66).

23- SCHOENBAUM, D.V.M.; BERAN, G.W.; MURPHY, D.P. Pseudorabies virus latency and reactivation in vaccinated swine. Am. J. Vet. Res., v.51, n.3, p.3348, 1990.
24- SIEGEL, S. Estatística não paramétrica. São Paulo : Mc Graw-Hill, 1975. 350p.

25- SILVA, R.A.; DOBEREINER, J. Nota sobre a doença de Aujeszky no Município de Sapucaia, Estado do Rio de Janeiro. Arqu. Inst. Biol. An., Rio de Janeiro, v.3, p.83-90, 1960.

26- SILVA, R.A.; GIÓVINE, N. Novos focos da doença de Aujeszky no Estado de Minas Gerais. I. Estudo do foco no Município de Almenara. Arqu. Inst. Biol. An., Rio de Janeiro, v.4, p.99-104, 1961

27- STEWART, W.C.; CARBEY, V.M.A.; KRESSE, J.I. Detection of pseudorabies virus by immunofluorescence. J. Am. Vet. Med. Assoc., v.151, n.6, p.747-51, 1967.

28- VANNIER, P. Efficiency of an inactivated virus vaccine against Aujeszky's disease for fattening pigs with or without passive immunity. In: Aujeszky's disease. Current Topics in Veterinary Medicine and Animal Science, v.17, p.18190, 1982.

29- VANNIER, P. Testing of Aujeszky's disease vaccines. In: AUJESZKY'S DISEASE O.I.E. Bangkok, Thailand, 1994. Symposium. p.23-31.

30- VANNIER, P.; HUTET, E.; BOURGUEIL, E.; CARIOLET, R. Vaccins contre la maladie d'Aujeszky et souches vaccinales delétés. Rec. Méd. Vét., v.166, n.12, p.1127-33, 1990.

31- WITTMANN, G.; RZIHA, H.J. Aujeszky's disease (pseudorabies) in pigs. In: WITTMAN, G. Herpesvirus diseases of cattle, horses, and pigs. Boston Kluwer Academic, 1989. p.230-325.

Recebido para publicação: 17/04/1997

Aprovado para publicação: 04/12/1997 